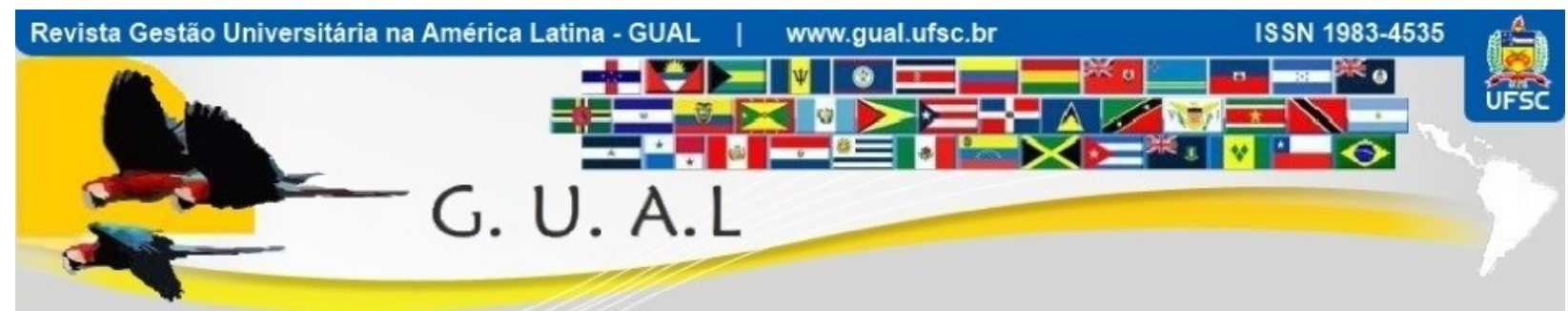

DOI: http://dx.doi.org/10.5007/1983-4535.2015v8n1p45

\title{
EXPANSÃO E INTERIORIZAÇÃO DAS UNIVERSIDADES FEDERAIS: UMA ANÁLISE DO PROCESSO DE IMPLEMENTAÇÃO DO CAMPUS DO LITORAL NORTE DA UNIVERSIDADE FEDERAL DA PARAÍBA
}

\begin{abstract}
EXPANSION AND INTERIORIZATION OF FEDERAL UNIVERSITIES: AN ANALYSIS OF THE IMPLEMENTATION PROCESS OF THE CAMPUS OF THE NORTH COAST OF THE FEDERAL UNIVERSITY OF PARAÍBA (BRAZIL)
\end{abstract}

Francivaldo dos Santos Nascimento, Mestre

Universidade Federal da Paraíba - UFPB

francivaldon@hotmail.com

Diogo Henrique Helal, Doutor Universidade Federal da Paraíba - UFPB e Fundação Joaquim Nabuco - FUNDAJ diogohh@yahoo.com.br

Recebido em 12/novembro/2013

Aprovado em 22/dezembro/2014

Sistema de Avaliação: Double Blind Review

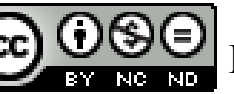

Esta obra está sob uma Licença Creative Commons Atribuição-Uso. 


\section{RESUMO}

O governo federal, desde 2004, tem se preocupado em expandir e interiorizar as universidades públicas federais. Diante desse contexto, a partir de 2005, a UFPB retomou o seu processo de interiorização, por meio da criação do Campus IV (Litoral Norte), localizado nas cidades de Rio Tinto e Mamanguape. Este artigo analisa o processo de implementação do Campus do Litoral Norte da UFPB. A fundamentação teórica abordou o ciclo de política pública, em particular a etapa de implementação, destacando o modelo de Smith (1973), e as políticas públicas de educação superior nos governos de FHC e Lula. A pesquisa foi descritiva e qualitativa, realizada por meio de estudo de caso. Os dados foram primários coletados por meio de entrevistas realizadas com nove pessoas, docentes e técnico-administrativos, que participaram diretamente do processo de implementação. Foram utilizados ainda dados secundários, tais como documentos institucionais, além de matérias jornalísticas publicadas na imprensa local. $\mathrm{Na}$ análise dos dados foi a de conteúdo. Os dados permitiram analisar o processo de implementação na perspectiva institucional, os aspectos político-institucionais; na perspectiva material, os aspectos técnico-administrativos; e na perspectiva processual, as relações com a sociedade. Os resultados da pesquisa revelaram que o processo de implementação do Campus do Litoral Norte teve uma influência política, principalmente na escolha das cidades que receberiam o campus. A implementação do Campus IV foi uma ação estratégica de enorme relevância educacional, social e econômica, levada a cabo, contudo, a partir de alguns equívocos como falta de planejamento adequado e dificuldades na execução das obras.

Palavras-chave: Políticas Públicas. Implementação. Interiorização das Universidades Federais.

\section{ABSTRACT}

The Brazilian federal government, since 2004, has been concerned with expand into the interior the federal public universities. In this context, from 2005, the UFPB recovered its internalization process, by the creation of the Campus IV (North Coast), located in the cities of Rio Tinto and Mamanguape. This article analyzes the implementation process of the Campus of the North Coast of UFPB. The theoretical foundation addressed the public policy cycle, in particular the implementation stage, highlighting the model of Smith (1973), and public policies of higher education in the FHC and Lula. The research was descriptive and qualitative, conducted through a case study. The primary data were collected through interviews with nine people, professors and technical administrators, who participated directly in the implementation process. Were also used secondary data, such as institutional documents, and newspaper articles published in the local press. The data analysis was the content analysis. The data allowed the analysis of the implementation process in the institutional perspective, the political and institutional aspects; in materials perspective, the technical and administrative aspects; and procedural perspective, relations with society. The survey results revealed that the implementation process had a political influence, especially in the choice of cities that receive the campus. The implementation of the Campus IV was a strategic action with an enormous educational, social and economic relevance, carried out, however, from some mistakes, as lack of proper planning and difficulties in the execution of infrastructure projects.

Keywords: Public Policy. Implementation. Interiorization of Federal Universities. 


\section{INTRODUÇÃO}

A educação superior tem experimentado a expansão em todo o mundo, inclusive em países periféricos, com vistas a garantir maior acesso, principalmente por parte das camadas sociais menos favorecidas (TEIXEIRA, et al; 2012; MCCOWAN, 2007).

Em particular, no Brasil, tivemos conjunto de iniciativas que buscaram a ampliação e interiorização do ensino superior implementadas pelo governo federal. Dentre essas iniciativas governamentais, destacam-se o Programa Expandir criado em 2005, o Programa de Apoio a Planos de Reestruturação e Expansão das Universidades Federais (REUNI) instituído por meio do Decreto No 6.096 de 24 de abril de 2007, e a criação do Programa Universidade para Todos (PROUNI).

Melo, Melo e Nunes (2009) identificaram três ciclos nesse processo, constituindo etapas da expansão recente das universidades federais brasileiras: o primeiro - Expansão para o Interior (2003/2006) - com a criação de aproximadamente dez novas universidades federais em algumas regiões e criação e consolidação de 48 campi universitários. Nesse período foi criado o programa Expandir que contemplou a Universidade Federal da Paraíba (UFPB), dando origem ao Campus IV - Litoral Norte, objeto de estudo deste artigo; o segundo Expansão com Reestruturação (2007/2012) - com adesão da totalidade das IFES com implantação de 95 campi, e que teve o REUNI como principal programa; e o terceiro Expansão com Ênfase nas Interfaces Internacionais - por meio da criação de universidades federais territoriais estratégicas, tais como a Universidade Federal da Integração LatinoAmericana (UNILA), sediada em Foz do Iguaçu (PR); Universidade Federal do Oeste do Pará (UFOPA), sediada em Santarém (PA); Universidade Luso-Afro-Brasileira (UNILAB) em Redenção (CE) e a Universidade Federal da Fronteira Sul (UFFS), sediada em Chapecó (SC).

O número de campi também cresceu com a criação de mais de 100, chegando em 2010 a 231 unidades. Com isso, o número de municípios atendidos pelas universidades federias passou de 114, em 2003, para 237, no final de 2011.

Diante desse processo de expansão das instituições públicas federais de ensino superior, a UFPB retomou, a partir de 2005, o seu processo de interiorização por meio da criação do Campus Litoral Norte, localizado nas cidades de Rio Tinto e Mamanguape-PB. Esse campus foi criado e teve seu funcionamento autorizado por meio da Resolução 05/2006 do Conselho Universitário (CONSUNI); sua implantação (etapa de interesse dessa pesquisa) começou a partir de março de 2006. 
Perez (2010) considera pertinente resgatar a utilidade de pesquisar a implementação de políticas educacionais, uma vez que essa fase é menos prestigiada pelos analistas. De acordo com Secchi (2010, p. 46), na pesquisa que analisa o processo de implementação, "o foco está centrado no processo de implementação per se, seus elementos, seus contornos, suas relações, seu desenvolvimento temporal, tem um objetivo mais descritivo que prescritivo". Nessa senda, este artigo objetiva descrever como ocorreu o processo de implementação o Campus do Litoral Norte da UFPB.

\section{POLÍTICAS PÚBLICAS}

Enquanto área de conhecimento e disciplina acadêmica, a política pública nasceu nos Estados Unidos, rompendo tradições europeias. Enquanto esta concentrava seus estudos no Estado, produtor de políticas públicas por excelência, aquele vislumbrava uma perspectiva diferente, enfatizando os estudos sobre a ação dos governos (SOUZA, 2006).

O conhecimento produzido pela área de políticas públicas vem sendo utilizado de forma ampla, por pesquisadores, políticos e administradores, com o objetivo de buscar soluções para problemas públicos. Essa utilidade mostra-se importante para quem estuda ou toma decisões políticas em áreas como saúde, educação, segurança, habitação, transporte, saneamento, meio ambiente, gestão pública, assistência, dentre outras (SECCHI, 2010).

Matias-Pereira (2010) destaca o crescente interesse da sociedade brasileira pela área de políticas públicas, na medida em que tem aumentado o envolvimento e também a conscientização sobre os efeitos dessas políticas na vida do cidadão, seja no âmbito local, regional ou nacional.

A sociedade espera diante dos inúmeros problemas existentes, em áreas como saúde, educação, segurança pública, meio ambiente, assistência social, e tantas outras, que o Estado inclua na sua agenda ações nesses campos, e implemente políticas públicas que venham atender às reais necessidades dos cidadãos.

\subsection{CONCEITOS DE POLÍTICAS PÚBLICAS}

Existem muitas definições sobre política pública, não havendo concordância sobre os possíveis limites de atuação dos seus protagonistas. As definições, contudo, quase sempre recaem sobre as ações do Estado como o principal agente, ou com outros atores da sociedade, na busca de soluções de problemas públicos. 
Souza (2006, p. 26) define políticas públicas como "o campo do conhecimento que busca, ao mesmo tempo, "colocar o governo em ação" e/ou analisar essa ação e, quando necessário, propor mudanças no rumo ou curso dessas ações.

Já Secchi (2010, p. 2) afirma que política pública “é uma diretriz elaborada para enfrentar um problema público". Para o autor (2010), deve contemplar dois elementos fundamentais: intencionalidade pública e resposta a um problema público. Höfling (2001), de outra parte, entende que as políticas públicas são as formas utilizadas pelo Estado para implementar um projeto de governo, e procura atingir um setor específico da sociedade por meio de programas e ações especialmente direcionadas.

\subsubsection{O ciclo de políticas públicas}

São quatro as principais etapas que fazem parte do ciclo de políticas públicas - a agenda, a formulação, a implementação e a avaliação. Tais fases são indispensáveis para os governantes na construção de políticas públicas com o objetivo de responder às diversas demandas da sociedade. Para fins deste trabalho abordaremos a fase de implementação.

O ciclo de políticas públicas (policy cycle) é um esquema em que se visualiza se e interpreta a vida de uma política pública de forma organizada, mostrando as fases sequenciais e interdependentes (SECCHI, 2010). A utilidade do ciclo está em ajudar a organizar ideias, na simplificação de uma política pública complexa, como também pode auxiliar políticos, administradores e pesquisadores a ter referencial, um comparativo para casos diferentes, constituindo um processo dinâmico e de aprendizado (SECCHI, 2010; SOUZA, 2006).

Para Rua (2009), a concepção do ciclo de políticas vem considerar a política pública como uma sequência de atividades políticas agrupadas que formam o processo político. Permite examinar o processo decisório, identificar e analisar processos políticoadministrativos, as estratégias na realização da política, bem como o comportamento dos diversos atores abrangidos nas diferentes etapas no processo de produção de políticas. As etapas do ciclo de políticas públicas não compreendem um processo linear; são, na verdade, marcadas pela contradição, com muitas etapas ocorrendo de forma simultânea.

\subsubsection{Implementação de políticas públicas}

A fase de implementação vem logo após a tomada de decisão dos policymakers. Essa etapa compreende o espaço temporal em que são produzidos os resultados concretos de uma política pública definida anteriormente (SECCHI, 2010; SILVA e MELO, 2000). 
Silva e Melo (2000, p.10) entendem a implementação "como um processo autônomo onde decisões cruciais são tomadas e não só implementadas". Já Rua (2009) identifica essa fase como um conjunto de atividades e eventos que sucede a definição das diretrizes de uma política, e incluem esforços para administrá-la, bem como impactos sobre pessoas e eventos. Dessa forma, um conjunto de decisões e ações realizadas por grupos ou indivíduos é direcionado para a consecução de determinados objetivos definidos anteriormente sobre uma determinada política.

Para Oliveira (2006), há problemas no planejamento dos países em desenvolvimento, mostrando a necessidade de essa etapa ser vista com um processo e não como um produto técnico. Smith (1973), por sua vez, destaca a diferença nos processos de implementação em países desenvolvidos e países em desenvolvimento. Para o autor (1973), os governos dos países em desenvolvimento tendem a formular políticas com grande amplitude, mas a burocracia governamental não tem capacidade de implementá-las, e os grupos de interesse, partidos de oposição e indivíduos e grupos afetados tentem influenciar a implementação da política. Segundo Smith (1973), os principais fatores que contribuem para essa incapacidade referem-se à falta de pessoal qualificado, gestão ineficiente e controle de líderes políticos, oposição à própria política e a corrupção.

As vicissitudes da implementação de programas governamentais, conforme argumentam Silva e Melo (2000), têm sido entendidas como uma variáveis nucleares na explicação do fracasso dos governos em atingir os objetivos estabelecidos nas políticas públicas. A implementação revelou-se, assim, como o "elo perdido" nas discussões de efetividade da ação governamental, pois problemas não antecipados, que surgem durante a implementação de políticas podem gerar obstáculos intransponíveis, e como consequência levar as agências responsáveis a descontinuá-las.

De acordo com Secchi (2010), no Brasil são inúmeros os exemplos de "leis que não pegam", "programas que não vingam", ou mesmo, projetos que deveriam solucionar problemas públicos que acabam muitas vezes desvirtuados no momento da implementação.

Uma questão bastante discutida entre os autores que se dedicam a estudar políticas públicas refere-se como deveria ser visto o processo de planejamento em relação à direção do fluxo de decisões na implementação de políticas públicas. Esse debate leva basicamente a dois modelos amplamente estudados de implementação de políticas públicas: o top-down e botton-up (MATIAS-PEREIRA, 2010; OLIVEIRA, 2006; SILVA e MELO, 2000). 
O modelo top-down (de cima para baixo) caracteriza-se pela clara separação entre o momento da decisão e o da implementação. Essa perspectiva parte de uma visão tecnicista, na qual as políticas públicas devem ser elaboradas e decidas pela esfera política, que é vista com uma "propriedade" dos policymakers que estão situados no topo das organizações. Nesse sentido, a implementação limita-se a mero esforço administrativo de encontrar meios para atingir os fins estabelecidos, e no caso de ocorrerem problemas nessa etapa, estes seriam entendidos como "desvios de rota". Assim, se os programas e ações estão bem planejados, uma implementação errada é considerada falha dos agentes implementadores, processo esse conhecido na literatura com blame shifting ou deslocamento de culpa (MATLAND, 1995; SILVA e MELO, 2000; OLIVEIRA, 2006; MATIAS-PEREIRA, 2010; SECCHI, 2010; LIMA e MEDEIROS 2012).

Silva e Melo (2000) consideram que a visão top-down corresponderia na burocracia pública ao ideal weberiano, e a percepção de cima para baixo estaria ancorada por uma série de em pressupostos ambientais - informação perfeita, recursos ilimitados, coordenação perfeita, controle, hierarquia, clareza de objetivos, linhas únicas de comandos. Além desses aspectos, faz-se necessário legitimidade política e consenso quanto à política a ser implementada.

No contraponto, o modelo botton-up (de baixo para cima) caracteriza-se pela maior discricionariedade dos burocratas pela presença de atores que se auto-organizam. Aqui, os implementadores têm maior participação não só para fazer um exame minucioso do problema, mas para buscar soluções para enfrentá-lo no decorrer da implementação (SECCHI, 2010; MATLAND, 1995).

É possível ainda falar em um terceiro modelo, decorrente da combinação dos dois anteriores. Nesse caso, aceita-se a importância dos dois fluxos (MATLAND, 1995). Oliveira (2006) tem observado avanços dos estudos sobre implementação, considerando ser mais adequado a convergências das duas perspectivas, unificando as variáveis macro dos modelos top-down com as variáveis micro dos modelos botton-up.

\subsection{POLÍTICAS PÚBLICAS DE EDUCAÇÃO SUPERIOR}

Ao tratar da política educacional, Höfling (2001) considera que o Estado deve ter como prioridade programas de ação universalizantes e assim possibilitar conquistas sociais a grupos e setores desfavorecidos com o objetivo de reverter o desequilíbrio social existente. A 
autora (2001) considera importante colocar à disposição os direitos sociais que inclui a educação, já que uma política educacional desempenha um importante papel numa sociedade desigual como a brasileira na formação de cidadãos, frentes aos desafios enfrentados no ambiente competitivo de economia globalizada.

Mesmo com grandes barreiras, esse é o contexto que tem inspirado inúmeras reformas vivenciadas nos últimos 20 anos na educação superior brasileira. A universidade, que remonta a sua efetivação no país há menos de um século, era sinônimo de forte elitização, cujo acesso era restrito a grupo privilegiado. Porém, a partir do governo Lula (2003 a 2010), houve mudanças no direcionamento de políticas que promoveram um aumento de acesso ao ensino superior no Brasil, por meio de programas como Prouni, UAB, Reuni (PEREIRA; SILVA, 2010).

Lima (2011), de outra parte, considera que as análises das políticas educacionais dos governos Fernando Henrique Cardoso e Lula da Silva demonstram um processo de prosseguimento de reformas neoliberais na educação superior no Brasil. Em geral, é possível afirmar que ambos os governos promoveram esforços na busca pela universalização do ensino superior no país, sendo o governo FHC, mais à direita, a partir do estímulo a instituições privadas de ensino superior, enquanto Lula, à esquerda, sobretudo a partir do fortalecimento das instituições públicas federais.

\subsubsection{Políticas Públicas de Educação Superior no Governo Lula (2003 a 2010)}

Os governos, principalmente em países em desenvolvimento tem adotado inúmeras políticas educacionais para promover maior acessibilidade à educação, condição sine qua non à novas oportunidades no mercado de trabalho. "Tal medida torna-se ainda mais necessária, visto que, historicamente, a mobilidade social ascendente nas sociedades capitalistas é dependente dos níveis educacionais aos quais os indivíduos têm acesso" (PEREIRA; SILVA, 2010, p. 13).

Considerando o caso brasileiro, Risttof (2006, p. 45) afirma que "se a palavra de ordem da década passada foi expandir, a desta década precisa ser democratizar". Para o autor (2006), não basta falar em expansão do campus, pois esta não é suficiente; há de se falar em democratização do campus. Expandir vagas no setor público significa transferir a alunos aquinhoados do setor privado para o setor público. Entretanto, criar novas instituições 
públicas e interiorizar as IFES, aumentar vagas, expandir o ensino a distância no setor público proporcionam alternativas reais na inclusão dos filhos de classes mais baixas.

Essa reflexões pautaram as ações do governo Lula, no que se refere as políticas públicas de acesso ao ensino superior. Os programas Expandir, Reuni, Prouni e UAB têm contribuído de forma significativa para o aumento no número de alunos com acesso ao ensino superior.

O Programa Expandir foi o primeiro passo do governo Lula para expansão da universidade pública. Durante o processo de implementação não houve uma legislação como em outros programas do governo federal. Foram enviados projetos de novos campi e universidades para o MEC, que mediante aprovação, promoveu a liberação de recursos para implantação.

Para o programa, foi previsto um investimento de $\mathrm{R} \$ 592$ milhões até o ano de 2007, com a criação de dez novas universidades e cerca de 50 novos campi, em 68 municípios espalhados pelo interior do país (MICHELOTTO; COELHO; ZAINKO, 2006; SOUSA JUNIOR, 2011).

Michelotto, Coelho, Zainko (2006), bem como Faria (2006), destacaram que o programa expandir adotou três formas para atingir a expansão com interiorização: criação de novas universidades, transformação de faculdades federais em universidades e a construção e consolidação de novos campi.

De acordo com Faria (2006), foram criadas quatro novas universidades nas seguintes localidades: a UFABC em Santo André, São Paulo; a Grande Dourados, no Mato Grosso do Sul; a universidade do Recôncavo Baiano, em Cruz das Almas, na Bahia; a universidade Pampa em Bajé, no Rio Grande do Sul.

Um total de seis faculdades federais foi transformado em universidades. Ainda, de acordo com o MEC, outra medida adotada no Expandir foi a construção de novos campi. Na primeira etapa desse programa foram criados ou consolidados 36 campi em 19 estados do Brasil. Nesta etapa, as universidades enviaram propostas para construir campus em regiões de difícil acesso. Na última etapa do Expandir foi realizada a construção de doze novos campi. A criação do Campus do Litoral Norte da UFPB ocorreu nesse momento.

\section{PROCEDIMENTOS METODOLÓGICOS $\backslash$}

A pesquisa foi classificada como descritiva, tendo em vista buscar descrever o processo de implementação do Campus do Litoral Norte na visão dos atores envolvidos. A 
abordagem adotada neste estudo foi a qualitativa, e com relação à estratégia de pesquisa foi empreendido um estudo de caso.

\subsection{CONTEXTO E ATORES DA PESQUISA}

O Campus IV da UFPB está localizado em duas cidades paraibanas- Mamanguape e Rio Tinto. A cidade de Mamanguape tem uma população de 42.303 habitantes (IBGE, 2010) e está a uma distância de $47 \mathrm{~km}$ de João Pessoa; Rio Tinto tem 22.976 habitantes e está situada a $64 \mathrm{~km}$ da capital. A distância entre as duas unidades do campus do Litoral Norte é em torno de $7 \mathrm{~km}$.

O referido campus oferece doze cursos de graduação, seis destes localizados em Mamanguape (Ciências Contábeis, Hotelaria, Letras, Pedagogia, Secretariado Executivo Bilíngue e Gastronomia) e outros seis em Rio Tinto (Antropologia, Ciências da Computação, Design, Ecologia, Matemática e Sistemas de Informação).

De acordo com os dados disponibilizados pela da Pró-Reitoria de Graduação da UFPB, nos 11 cursos de graduação já implantados no Campus do Litoral Norte constavam 2.676 alunos matriculados na graduação em março de 2013.

A definição na escolha dos entrevistados ocorreu de forma intencional: recorreu-se a pessoas da UFPB que participaram do processo de criação e implantação do campus IV. Dessa forma, foram entrevistados três professores, sendo dois ex-diretores do campus e o atual vice-diretor. Também foram entrevistados seis servidores técnico-administrativos que exerceram diferentes cargos e atribuições no Campus do Litoral Norte.

\subsection{O PROCESSO DE COLETA DOS DADOS}

Os dados foram coletados de fontes primárias por meio de entrevistas semiestruturadas com os atores envolvidos no processo de implementação do Campus do Litoral Norte, realizadas entre os meses de dezembro de 2012 e fevereiro de 2013. Essas entrevistas foram gravadas por meio digital e posteriormente transcritas na íntegra. No total foram mais de seis horas de gravação com uma média de 43 minutos por entrevista. Os dados secundários se referem às informações contidas em documentos da UFPB (Resoluções e atas de reunião do CONSUNI referente a criação do Campus IV). Foi ainda realizada uma pesquisa nos jornais e portais de notícias do Estado da Paraíba (clipagem de notícias disponibilizada pela UFPB), com matérias relacionadas ao processo de criação do Campus do Litoral Norte. 


\subsection{ANÁLISE DOS DADOS}

Para compreender o processo de implementação do campus do Litoral Norte da UFPB foi utilizado o método de análise de conteúdo, e em particular, a análise temática.

Segundo Bardin (2011), a análise de conteúdo visa obter por meio da análise das comunicações interpretar procedimentos, sistemáticos e objetivos de descrição do conteúdo das mensagens, com indicadores que sejam quantitativos ou não, mas permitem a inferência de conhecimentos relativos às condições de produção/recepção das variáveis inferidas dessas mensagens".

Para Bardin (2011), a análise temática permite descobrir "núcleos de sentido" que compõem a fala e sua presença ou frequência podem significar alguma coisa para o objetivo escolhido.

Foram utilizadas como referência as perspectivas de estruturação definida por Frey (2000), institucional, processual e material, conforme o autor indicou para estudos de casos, e o modelo do processo de implementação de Smith (1973).

$\mathrm{Na}$ Figura 1 estão relacionadas as perspectivas, dimensões e categorias analíticas delineadas pelo referencial teórico que foram usados na elaboração dos roteiros de entrevistas e utilizadas na análise.

\begin{tabular}{|c|c|c|}
\hline PERSPECTIVA & DIMENSÃO & CATEGORIAS ANALÍTICAS \\
\hline Institucional & $\begin{array}{l}\text { Aspectos Político- } \\
\text { institucionais }\end{array}$ & $\begin{array}{l}\text { - Concepção do programa (política } \\
\text { idealizada); } \\
\text { - Relações entre os implementadores; } \\
\text { - Organização implementadora. }\end{array}$ \\
\hline Material & $\begin{array}{l}\text { Aspectos Técnico- } \\
\text { administrativos }\end{array}$ & $\begin{array}{l}\text { - Localização; } \\
\text { - Recursos disponibilizados; } \\
\text { - Dificuldades na implantação do campus. }\end{array}$ \\
\hline Processual & Relações com a sociedade & $\begin{array}{l}\text { - O processo de criação do Campus; } \\
\text { - O processo de criação e implantação dos } \\
\text { cursos; } \\
\text { - Impactos da implantação do campus. }\end{array}$ \\
\hline
\end{tabular}

Figura 1 Perspectivas, dimensões de análise com as respectivas categorias analíticas.

Fonte: Elaborado pelos Autores (2013).

Para realizar a operacionalização das análises procedeu-se a codificação. Os nove entrevistados foram assim identificados: Entrevistado 1 (Gestor Administrativo); Entrevistado 2 (Bibliotecária); Entrevistado 3 (Administradora); Entrevistado 4 (Ex-Diretor); Entrevistado 5 (Economista); Entrevistado 6 (Assistente em Educação); Entrevistado 7 (Técnico em Assuntos Educacionais); Entrevistado 8 (Ex-Diretor); e Entrevistado 9 (Vice-Diretor). 


\section{ANÁLISE DOS RESULTADOS}

\subsection{ASPECTOS POLÍTICO-INSTITUCIONAIS}

Nesta seção, busca-se compreender os aspectos políticos e institucionais que estiveram presentes no processo de implementação do Campus do Litoral Norte. As seguintes categorias estão contempladas nessa dimensão: a política idealizada (concepção do programa); a relação com o governo federal e demais instituições; e a organização implementadora.

\subsubsection{Política idealizada (concepção do Programa do Expandir)}

O cenário de meados da década de 2000 não era favorável à universidade pública, tendo em vistas as restrições e dificuldades financeiras enfrentadas pelas universidades federais, ao mesmo tempo em que havia um movimento de facilitar a abertura de instituições privadas.

De acordo com Sousa Junior (2011), esse processo de sucateamento e contingenciamento começou a ser revertido, tendo em vista o início de uma nova fase, com uma política de investimento nas instituições federais de ensino superior, que iniciou com o programa Expandir em 2005 e o REUNI em 2007. O Expandir veio como um ousado esforço de interiorizar as universidades federais, com um investimento previsto de mais de 500 milhões de reais com a criação de novas universidades e 48 novos campi em diversas cidades interioranas do país. Para concretizar a parceria com as prefeituras que fossem receber o campus, seria necessário providenciar um local, que a mesma dispusesse, ou realizar alguma desapropriação e ceder à universidade a área para a universidade implantar o campus.

O slogan do Expandir "Universidade, expandir até ficar do tamanho do Brasil", revela a clara intenção do MEC de ampliar e fortalecer a expansão das universidades federais em todo o país (COSTA, 2009).

Nesse contexto, a UFPB aderiu ao Programa e elaborou o projeto que criou o Campus IV. As primeiras discussões começaram em meados de 2005 e prolongaram-se ao longo do ano. Só no início de 2006 foi aprovado o projeto da UFPB pelo MEC e também criado oficialmente esse campus pelo CONSUNI. Essa unidade acadêmica foi criada com o propósito de oferecer educação superior na região polarizada pelas cidades de Rio Tinto e Mamanguape, situadas a cerca de $50 \mathrm{~km}$ da sede da UFPB em João Pessoa. 
A interiorização das universidades federais, que se concretizou por meio do Programa Expandir a partir de 2005, e que levou educação superior para as cidades distantes dos grandes centros urbanos, foi considerada por todos os entrevistados como positivo:

Eu acho isso muito positivo, muito interessante... Algumas universidades fizeram de maneira muito acertada, seguindo esse propósito, que seria levar a instituição federal a lugares mais distantes, a regiões que fossem capazes de absolver a instituição e os seus usuários. (ENTREVISTADO 4).

O Programa Expandir foi elaborado de forma centralizada pelo governo federal com o objetivo de ser executado da mesma forma em todo o país. Lima e Medeiros (2012) afirmam ser esse o modelo comum de formulação e implementação de programas pelo governo brasileiro. O modelo atual praticado na construção de políticas públicas, denominado por alguns autores como recentralização ou coordenação ou federativa, constitui-se de políticas pensadas nacionalmente, como grandes padrões gerais de funcionamento, e a partir disso são formadas parcerias e incentivos para operacionalizar a implementação no nível local. Faz-se necessário, assim, a devida adaptação da política pública a diferentes contextos locais (ARRETCHE, 2004; LOTTA, PAVEZ, 2010). Foi o que aconteceu, quando da criação e implantação do Campus IV da UFPB.

O governo federal, quando criou o programa de expansão, buscou rapidez para concretizá-lo. Não criou nenhuma norma jurídica, decreto, portaria ou algo do gênero, como fez em seguida para colocar em prática o Reuni. Apenas fez o lançamento do referido programa e convidou as universidades federais a enviarem seus projetos. À medida que eram aprovados já deveriam iniciar as primeiras ações, tais como a contratação de professores e técnicos, fazer vestibular e encontrar um local apropriado junto às prefeituras. Todas essas ações levaram tempo, e nem sempre essas providências foram tão céleres quanto o necessário, como apontou o entrevistado a seguir: "O governo toma essa atitude de interiorizar e meio que atropelada o governo já busca colocar isso em funcionamento e tornar isso um fato consumado pra que não houvesse risco de uma interrupção nesse processo de interiorização". (ENTREVISTADO 5).

De acordo com Faria (2006), o Programa Expandir seria implementado da seguinte forma: após a definição das cidades e locais, os novos campi e universidades seriam construídos com a participação da comunidade e em parceria com as prefeituras. Estas cediam áreas para as obras e opinam sobre quais cursos querem e de que forma seriam ofertados. $\mathrm{O}$ MEC, enquanto como órgão central responsável pela criação desse programa, pagaria os 
serviços licitados, a contratação de trabalhadores da construção civil e professores e pessoal técnico-administrativo, além de custear a aquisição de equipamentos e laboratórios.

Com relação a esse processo de interiorização, a UFPB, a princípio, pareceu bastante confortável, tendo em vista a sua história como uma universidade que sempre teve campi distantes da sua sede. Inclusive, sempre foi enfatizada pela própria comunidade acadêmica, essa sua vocação para interiorização.

No ano de 2002, a UFPB passou pelo processo de desmembramento de quatro, dos seus sete campi, tendo em vista a criação da Universidade Federal de Campina Grande (UFCG), a partir do campus da UFPB em Campina Grande e em outras cidades da região. A partir de então, a UFPB ficou composta pelos campi de João Pessoa, Areia e Bananeiras. Em 2005, A Universidade retomou essa interiorização com a criação do Campus IV.

\subsubsection{Relações entre os implementadores}

A criação do Campus do Litoral Norte envolveu algumas instituições para que fosse possível concretizar essa política de interiorização do ensino superior. Estiveram envolvidos diretamente, o governo federal por meio do MEC, a universidade que pleiteava um novo campus, a UFPB, e as prefeituras anfitriãs do campus, no caso as de Rio Tinto e Mamanguape.

Cada uma das instituições tinha algumas funções bem específicas. Ao MEC caberia aprovar o projeto do campus, repassar os recursos orçamentários para a execução da infraestrutura, bem como, a contratação de docentes e técnico-administrativos. A universidade ficou responsável pela implantação do campus, conforme definido no projeto aprovado pelo MEC e pelas instâncias acadêmicas. A cada município que fosse receber a universidade, caberia disponibilizar uma determinada área para construção do campus.

O fluxo de atribuições entre as instituições participantes na implementação de políticas públicas mostra-se de fundamental importância para alcançar os objetivos propostos. Lotta e Pavez (2010) afirmam que na implementação é comum encontrar diferenças na forma como a política foi formulada e de fato como foi executada. É comum isso acontecer nas políticas públicas instituídas no nível federal, com diretrizes já definidas e implantadas no nível local.

Com relação aos modelos teóricos que deram suporte à análise, foi verificado que a implementação do Programa Expandir contemplou característica tanto top-down quanto botton-up. Top-down quando, de um lado, o governo federal propôs uma orientação de criar 
campi em cidades do interior, e de outro as universidades tiveram que elaborar seus projetos nessa direção, não havendo margens para possibilidades diferentes. Botton-up, quando se observou, na prática, a dinâmica e relações que existiram na implementação, os diálogos para definir as cidades que receberiam o campus, quais e quantos cursos que seriam oferecidos, e o cronograma de implantação, aspectos que ficaram a cargo da organização implementadora.

\subsubsection{A organização implementadora}

Nesta subseção são descritos os procedimentos que foram utilizados pela UFPB para implementar o campus. Buscou-se descobrir como foi planejado o campus e qual a percepção dos entrevistados acerca da forma que a UFPB conseguiu gerenciar esse processo de implementação. Refere-se à dimensão organizativa, pois considera nessa perspectiva que o papel dos gestores é um essencial, já que são elos fundamentais para que a política pública possa de fato ser executada de acordo com o planejado.

Nesse momento também aconteceram jogos de poderes, e as negociações representaram outro aspecto essencial das dinâmicas organizacionais, acompanhando os processos de decisões e a implementação das políticas públicas.

Secchi (2010) enfatiza a importância de gerenciar a implementação, tendo em vista ser este o momento em que as funções administrativas, como por exemplo, liderança e coordenação são postos à prova. Aos atores encarregados de liderar o processo de implementação são exigidas competências pessoais para entender aspectos motivacionais dos atores que estão envolvidos no processo, para superar os obstáculos técnicos e legais existentes, identificar as deficiências da organização e os conflitos potenciais, assim como atuar diretamente nas negociações.

O planejamento, sem dúvida, torna-se também um elemento importante, para que a organização que está executando o projeto possa ter uma orientação clara, objetiva e bem definida, e assim evitar ambiguidades nas diversas etapas da implementação. Inclusive porque na dinâmica de implantação aqui estudada houve uma sobreposição de tarefas, com afirmaram os entrevistados 4 e 8 , ex-diretores do campus, e o que dificultou a execução do projeto:

[...] era implantar e construir ao mesmo tempo, isso significa, que isso representou, melhor dizendo, um acúmulo de tarefas da administração, tanto acadêmicas quanto da própria implantação física do projeto, isso criou descompassos nas rotinas da instituição[...] Então, eu não sei dizer se esta foi ou seria a melhor forma de fazer ou se teríamos apenas essa forma de fazer, o fato é que tivemos inúmeros problemas por causo disso, ter que 
aderir ao programa Expandir, abrir vagas, abrir os cursos, fazer seleção do vestibular... (ENTREVISTADO 4).

Observou-se que a UFPB teve dificuldades na implantação, já que não fez um planejamento estruturado como se esperava. Tratava-se de ação importante para instituição, mas ao mesmo tempo complexa, tendo em vista a criação e implantação de um campus dividido em duas cidades.

\subsection{ASPECTOS TÉCNICO-ADMINISTRATIVOS}

De acordo com Matias-Pereira (2010) para gerir o funcionamento da política pública, faz-se necessário de um aparato técnico-administrativo amparado por uma estrutura burocrática. Situa-se na perspectiva policy, definida por Frey (2000) como a responsável pela configuração dos programas políticos e dos problemas técnicos, bem como do conteúdo material das decisões políticas. Neste aspecto, as seguintes categorias de análises foram consideradas: localização e recursos disponibilizados.

\subsubsection{Localização}

Nesta categoria buscou-se obter dos entrevistados a percepção que os mesmos tiveram da implantação do Campus do Litoral Norte dividido para duas cidades: Rio Tinto e Mamanguape, visto ser singular para a UFPB essa forma de organização acadêmica.

Os entrevistados alegaram que o campus foi dividido por não haver um local adequado no limite dos dois municípios e por falta de consenso em qual das cidades deveria ficar o campus. Uma série de adequações foram feitas, tendo em vista que no projeto constava que seria em apenas um local, numa área de divisa entre as duas cidades.

Lotta e Pavez (2010) afirmam que as políticas concebidas a nível federal podem ser adaptadas de maneira que se aproxime da realidade local, visto a necessidade de diálogo com as diferentes realidades na implementação da política pública. Essas transformações, para além da ideia de erros ou interesses escusos de alguns atores, são uma consequência natural do próprio processo de ligar a formulação à implementação.

A UFPB teve que se adequar a essa nova realidade na implantação. A Universidade usou, portanto, de sua discricionariedade permitida pela política de expansão. De acordo com os relatos de alguns entrevistados, a implementação do Campus IV teve forte cunho político, sobretudo na definição da cidade onde seria implantado o campus. 
O plano de expansão da UFPB foi entregue ontem pelo reitor, Rômulo Polari ao secretário executivo de Ministério da Educação. Um novo encontro aconteceu com a liderança do PMDB no Senado Federal durante audiência que contou com presença de boa parte da bancada Federal paraibana. (JORNAL CORREIO DA PARAÍBA - 19/01/2006).

Esse "jogo político" teve um papel importante na aprovação do projeto da UFPB, assim como foi decisivo na definição que o Campus IV, tendo em vista que inicialmente era para ser instalado apenas em uma cidade, Mamanguape. Depois de reuniões com parlamentares, sobretudo do PMDB partido da prefeita de Rio Tinto àquela época, a UFPB não chegou a consenso em relação a cidade a ser escolhida, e optou por um local que seria na divisa das duas cidades. A escolha de tal local, contudo, não se mostrou viável, e o campus findou por ser construído nas duas cidades.

Para Secchi (2010), os políticos são representantes legítimos e possuem acesso privilegiado às esferas do poder estatal. Os políticos representam seus próprios interesses, bem como de seus partidos políticos, e também de áreas geográficas. No caso em estudo, essa mobilização dos políticos paraibanos, em prol da criação do Campus IV, justifica-se pela visibilidade que tem campus de uma universidade em uma cidade do interior, e também para demonstrar que os parlamentares estão empenhados em trazer benefícios para a região.

Os entrevistados 1, 3 e 4 descrevem as dificuldades advindas na gestão do campus em virtude da divisão. Foram relatadas disputas desde o início entre as duas unidades, de tal modo que houve muitos problemas na adaptação a essa forma de organização, tanto para quem estava gerenciando, quanto para quem exercia as atividades operacionais nas duas unidades. Foi necessário fazer muitas adequações, e nesse momento os "burocratas de rua" exerceram sua discricionariedade.

O entrevistado 5 relata que essa configuração do campus teve muitos pontos negativos, como o aumento do custo das obras, já que houve a necessidade de construir duas bibliotecas e mais de um laboratório, por exemplo. Essa percepção é corroborada pelo entrevistado 6 .

\subsubsection{Recursos disponibilizados}

Para Rua (2009), é a etapa de implementação do ciclo da política pública, que faz a política sair do papel. E para que isso aconteça são necessários vários aspectos administrativos como provisão de recursos orçamentários, formação de equipes, realização da 
parte legal-formal na contratação de servidores, como também aquisições de bens e contração de serviços.

De acordo com Sousa Junior (2011), no processo de implementação do Campus IV houve problemas com relação aos recursos humanos, particularmente quanto aos servidores técnico-administrativos, que inicialmente foram alocadas em número insuficiente. A dificuldade em relação ao corpo docente era fazer com que ele permanecesse no campus, pois para os que detinham maior qualificação sempre havia a possibilidade de enorme mobilidade, para o campus João Pessoa, agravada pelo fato de surgirem oportunidades de concurso para docentes em diversas universidades públicas que tiveram um crescimento exponencial nos últimos anos.

O projeto de criação do Campus IV previa a contratação de 280 professores até 2010 para os 12 cursos de graduação inicialmente previstos e de 342 técnico-administrativos. Conforme dados da Pró-Reitoria de Gestão de Pessoas (PROGEP), em janeiro de 2013, estavam lotados no Campus IV, 155 docentes de $3^{\circ}$ grau e 51 servidores técnicoadministrativos. Pela quantidade de fato em exercício, é possível perceber que o número de servidores e professores ficou muito aquém do que era inicialmente previsto.

Dessa forma, fica evidente a importância desses burocratas na implantação do campus, principalmente, quem exerceu cargos de gestão, que tiveram de buscar soluções para os inúmeros problemas que apareceram na implementação. Como o número de professores e funcionários não foi contemplado em número suficiente, houve comprometimento em muitos momentos dos propósitos da interiorização. Tal fato se observa quando se compara o número de vagas de processo seletivo para alunos previsto e efetivado. A oferta de vagas ficou muito aquém do planejado, em função, segundo relatos, do número insuficiente de professores, que impossibilitou a abertura de mais turmas, tanto no horário matutino quanto noturno, aproveitando a infraestrutura ociosa nesses horários.

Com relação aos recursos orçamentários, o entrevistado 8, que foi diretor do campus, foi enfático ao afirmar que não houve problemas com relação aos recursos orçamentários: "Dinheiro, não faltou! Dinheiro, não faltou!". Para ele a maior dificuldade foi lidar com a burocracia pública, licitações, pregões, pois tudo isso tem um trâmite, que compromete a celeridade muitas vezes requerida a execução das obras. 
Dessa forma, ficou evidente que com relação aos recursos orçamentário-financeiros a UFPB não teve problemas, uma vez que o governo federal repassou o que havia estava pactuado ao criar o programa Expandir.

Rua (1997) destaca a importância da disponibilidade de recursos financeiros para a implementação de políticas públicas, por se tratar de condição fundamental. Entretanto, para que seja satisfatório o processo de implementação é necessário que em cada estágio da implementação, haja uma combinação e efetivação de recursos de outra natureza.

\subsection{RELAÇÕES COM A SOCIEDADE}

Apresenta-se aqui a relação da UFPB com a sociedade no processo de implementação do Campus do Litoral Norte. Busca descrever como ocorreu a interação com comunidade acadêmica, a comunidade educacional da região, prefeituras e demais entidades que recepcionaram a criação e implantação Campus IV. Dessa forma, foram identificados os tipos de atores participantes do processo de implementação, os diálogos da universidade com os respectivos agentes, bem como as contribuições e resultados dessas interações.

O direcionamento atribuído à dimensão processual nos estudos sobre políticas públicas procura compreender com maiores detalhes a gênese e o percurso de certos programas políticos, os fatores favoráveis e os entraves bloqueadores, já que podem sofrer alterações ao longo do tempo. Neste contexto, destacam-se a a importância dos arranjos institucionais, as atitudes e objetivos dos atores políticos, bem como os instrumentos de ação e as estratégias políticas (FREY, 2000).

No processo de implementação do Campus do Litoral Norte, identificou-se pelo menos três períodos de maior interação com a sociedade: 1) Em agosto de 2005, quando ocorreu um encontro na cidade de Mamanguape com grande participação popular, momento que antecedeu a criação do campus; 2) Em março de 2006, quando da reunião do CONSUNI, órgão deliberativo que representou a comunidade acadêmica da universidade na matéria que discutiu e aprovou projeto de criação e implantação do campus do Litoral Norte; 3) Posteriormente, quando da participação da comunidade de Mamanguape e Rio Tinto em reuniões com gestores da UFPB, ocasiões em que foram discutidos diversos aspectos, como implantação de novos cursos. O curso de letras, por exemplo, foi criado a partir dessas reuniões, conforme relatos dos entrevistados, atendendo à necessidade da região nessa área. 
Tal preocupação de envolver diversos atores no processo de implementação de políticas públicas é uma concepção contemporânea. Para Oliveira (2006), essa é uma visão popular, politicamente correta, pois busca incorporar as contribuições da população no planejamento e na implementação de políticas públicas, uma vez que nos dias atuais a participação da sociedade civil mostra-se de fundamental importância na concretização de políticas governamentais.

\section{CONSIDERAÇÕES FINAIS}

Verificou-se que a UFPB se posicionou de forma bastante positiva na criação do Campus do Litoral Norte na política de expansão do ensino superior público federal. Ao definir que nas cidades de Rio Tinto e Mamanguape seria implantado um campus, fez com que esses municípios entrassem no mapa da inclusão da educação de nível superior e contribuiu decisivamente para que mais pessoas que residem na região que abrange o Campus do Litoral Norte tivessem acesso a esse nível de ensino.

Percebeu-se, nos aspectos político-institucionais no processo de implementação do Campus, uma forte atuação política, principalmente na etapa de elaboração do projeto de criação do campus, culminando na sua separação em dois municípios. Ressalte-se que essa decisão foi um divisor para a estrutura acadêmica atualmente existente, podendo ser configurado um processo de dependência de trajetória. Neste caso estudado, a trajetória de desenvolvimento do Campus do Litoral Norte é dependente dessa divisão em duas cidades, que tem ocasionado ao longo de quase uma década de existência uma série de problemas de gerenciamento, influenciando decisivamente a sua trajetória.

Ficou evidente no processo de implementação do Campus do Litoral Norte, as fragilidades nos elos entre as instituições. Os municípios de Mamanguape e Rio Tinto conseguiram atender a parte que lhes competia, que foi providenciar o terreno para a construção do campus. Entretanto, a demora em disponibilizar o local comprometeu o tempo previsto para implantação. O programa Expandir foi criado de forma que envolveu o governo federal, as universidades federais e municípios. Para Rua (2009), uma política quando abrange diferentes níveis de governos e em diferentes regiões do país, tende a apresentar uma implementação problemática, em função de que muitos fatores podem dificultar a interlocução entre as instituições parceiras, e problemas de coordenação e controle. 
Com relação aos aspectos técnico-administrativos no processo de implementação do Campus, verificou-se que faltou um planejamento adequado, tendo em vista uma série de dificuldades, sobretudo na execução das obras. As dificuldades surgiram a partir do governo federal, que não liberou vagas de docentes e técnico-administrativos na quantidade esperada e no tempo adequado. De outra parte, a UFPB teve enormes dificuldades ao se deparar com problemas práticos da implantação, principalmente no que se refere ao ritmo das obras na construção do campus, o que gerou insatisfação de toda a comunidade acadêmica das duas unidades.

Observou-se ainda que os implementadores situados nos níveis administrativos mais próximos dos usuários do campus do Litoral Norte tiveram que lidar com enormes dificuldades para conseguir dar ritmo às etapas previstas na implantação do campus.

$\mathrm{Na}$ análise da relação da UFPB com os atores da sociedade na implementação do Campus do Litoral Norte, percebeu-se que houve um acentuado diálogo com a comunidade no processo de implementação dessa unidade acadêmica. Essa dinâmica de interlocução com a comunidade anfitriã do campus e acadêmica mostrou-se bastante positiva, tendo permitido a criação do curso de Letras, demanda daquela região.

Mesmo com limitações, o Campus do Litoral Norte aproxima-se da fase de conclusão de sua implantação. Pode-se evidenciar os resultados positivos, a boa atratividade dos cursos ofertados e o crescimento da pós-graduação em nível de Mestrado, que já conta com dois cursos acadêmicos.

Por fim, considera-se que a criação desse campus foi uma ação estratégica de enorme relevância não só educacional, mas também, social e econômica, na medida em que tem contribuído na formação de pessoas da região de abrangência do campus, que vislumbram novas possibilidades a partir do acesso ao ensino superior

Sugere-se a realização de novos estudos no campus em questão, avaliando, por exemplo, os impactos do campus nas cidades de Rio Tinto e Mamanguape, e aferindo indicadores educacionais, sociais e econômicos após a chegada do campus. Considera-se também pertinente realizar uma pesquisa de casos múltiplos, fazer estudos em outras universidades para analisar como foi realizado nessas instituições o processo de criação de campus nas cidades do interior nos últimos anos, e assim ter uma visão mais ampla desse processo. 


\section{REFERÊNCIAS}

ARRETCHE, M. Federalismo e políticas sociais no Brasil: problemas de coordenação e autonomia. São Paulo em Perspectiva, São Paulo, v. 18, n. 2, p. 17-26, 2004.

BARDIN, L. Análise de conteúdo. São Paulo: Edições 70, 2011.

COSTA, S. Análise do conteúdo das matérias sobre expansão Universitária veiculadas por jornais de grande Circulação no estado do ceará no período de 2005-2008.

Dissertação. UFC. Mestrado Prof. em Políticas Públicas e Gestão da Educação Superior. Fortaleza, 2009.

FARIA, S. Aumentam para 48 os projetos de expansão universitária. 2006.

portal.mec.gov.br/index.php?option $=$ com_content\&view $=$ article\&id $=6729 \&$ catid $=212 \&$ Itemi $\mathrm{d}=86$. Acesso em: 09 junho. 2012.

FREY, K. Políticas públicas: um debate conceitual e reflexões referentes à prática da análise de políticas públicas no Brasil. Planejamento e Políticas Públicas, v.21, p.211-59, 2000.

HÖFLING,E. Estado e políticas (públicas) sociais. Cadernos Cedes, v21, n55, p.30-41, 2001.

IBGE. Disponível em: http://www.ibge.gov.br/cidadesat/topwindow.htm?1. Acesso em 21 de fev. 2013.

JORNAL CORREIO DA PARAÍBA - Cidades. 19/01/2006).

LIMA, K. R. S. O Banco Mundial e a educação superior brasileira na primeira década do novo século. R. Katál, Florianópolis, v. 14, n.1, p. 86-94, jan./jun. 2011.

LIMA, M.; MEDEIROS, J. J. Empreendedores de políticas públicas na implementação de programas governamentais. Rev. Adm. Pública, Rio de Janeiro, v. 46, n. 5, Oct. 2012.

LOTTA, G. S.; PAVEZ, T. R. Agentes de implementação: mediação, dinâmicas e estruturas relacionais. Cadernos Gestão Pública e Cidadania, São Paulo, v. 15, n. 56, 2010.

MATIAS-PEREIRA, J. Manual de Gestão Pública Contemporânea. S Paulo: Atlas, 2010.

MATLAND, R. E. Synthesizing the implementation literature: the ambiguity-conflict model of policy implementation. Journal of Public Administration, Houston, v 5, n 2.1995.

MCCOWAN, T. Expansion without equity: An analysis of current policy on access to higher education in Brazil. Higher Education, v. 53, n.5, p. 579-598. 2007.

MEC. Ministério da Educação. O programa. Disponível em:

$<$ http://portal.mec.gov.br/prouni/index.php?option=com_content\&task=view\&id=124\&Itemi $\mathrm{d}=140>$. Acesso em: 10 janeiro de 2013.

MICHELOTTO, R.; COELHO, R.; ZAINKO, M. A política de expansão da educação superior e a proposta de reforma universitária do governo Lula. Educar, n. 28, 179-98, 2006. 
OLIVEIRA, J. A. P. Desafios do Planejamento em Políticas Públicas: diferentes visões e práticas. RAP Rio de Janeiro 40(2):273-88, Mar./Abr. 2006.

PEREIRA, T. I. ; SILVA, L. F. S. C. As Políticas Públicas do Ensino Superior no Governo Lula: expansão ou democratização? Revista debates (UFRGS), v. 4, p. 10-31, 2010.

PEREZ, J. R. R. Por que Pesquisar Implementação de Políticas Educacionais Atualmente?

Educ. Soc., Campinas, v. 31, n. 113, p. 1179-1193, out.-dez. 2010.

RESOLUÇÃO No 05/2006. Conselho Universitário. UNIVERSIDADE FEDERAL DA PARAÍBA - Autoriza a implantação do Campus IV da Universidade Federal da Paraíba (Litoral Norte). 2006.

RISTTOF, D. Universidade Brasileira Contemporânea: Tendências e Perspectivas.

MOROSINI, M. (org). Universidade no Brasil: concepções e modelos. Brasília: INEP, 2006.

RUA, M. G. Análise de Políticas Públicas. Washington, Indes. BID, 1997.

RUA, M. G. Políticas Públicas - Florianópolis: Departamento de Ciências Administrativas/UFSC; [Brasília]: CAPES: UAB, 2009.

SECCHI, L. Políticas Públicas: Conceitos, Esquemas de Análise, Casos Concretos. São Paulo: Cengage Learning, 2010.

SILVA, P. L. B.; MELO, M. A. B. O processo de Implementação de Políticas Públicas no Brasil: Características e Determinantes da avaliação de Programas e Projetos.

UNICAMPI/NEPP 2000. Disponível em: http://www.nepp.unicamp.br/index.php?p=42.

Acesso em 30 de jun. de 2012.

SMITH, T. B. The policy implementation process. Policy Sciences, v.4, n.2, p.197-209, 1973.

SOUSA JUNIOR, L.. A expansão da universidade pública: uma experiência de democratização do ensino superior. In: XXV Simpósio brasileiro e II Congresso Iberoamericano de política e administração da educação, 2011, São Paulo. Anais... Anpae, 2011.

SOUZA, C. Políticas Públicas: uma revisão da literatura. Sociologias, ano $8, n^{\circ} 16$, jul/dez 2006. P. 20-45.

TEIXEIRA, P. N; ROCHA, V; BISCAIA, R; CARDOSO, M. F. Competition and diversity in higher education: an empirical approach to specialization patterns of Portuguese institutions. Higher Education, v.63, n.3, p.337-352 Mar. 2012. 